\title{
Reimagining academic identities in response to research demands at Universities of Technology
}

\author{
Thobani Gumbi ${ }^{1}$ and Sioux McKenna ${ }^{2}$ \\ ${ }^{1}$ Durban University of Technology \\ ${ }^{2}$ Rhodes University \\ Corresponding Author: thobanig@dut.ac.za
}

(Submitted: 25 November 2019; Accepted: 8 April 2020)

\begin{abstract}
In the last volume of this journal, Garraway and Winberg called for a reimagination of Universities of Technology (UoT) within the South African higher education system. This article continues that conversation by looking at the implications that the formation of the UoT had for academics' identities. Technikon lecturers' identities were closely tied to workplace expertise, but demands for research in UoTs have changed this. A social realist analysis of interviews with fifteen academics at three UoTs finds that research remains a contested issue. Interviewees understood research to take the form of acquiring postgraduate qualifications, rather than as an ongoing activity tied to their identities. Echoing Garraway and Winberg's study, the bureaucratic nature of the institutional culture was referred to as a constraint. There was also a view that for this programme, Dental Technology, a demand for research was needed from industry if this was to be a valued aspect of academics' identities.
\end{abstract}

Keywords: agency, bureaucracy, culture, institutional culture, knowledge structures, social realism, structure

\section{Introduction}

The development of academic identities is conditioned by institutional culture. The one can complement and enable the other or, conversely, contradict and constrain it. In a recent issue of this journal, Garraway and Winberg (2019) reflected on the institutional culture of Universities of Technology. Their focus at the institutional level was premised on the idea that the culture of an institution emerges through the beliefs and practices of individuals. This article works in conversation with that piece but comes at the interplay between academic identities and institutional culture from the other direction; we report on interviews with fifteen academics from three institutions to analyse how they conceived their identities within the University of Technology workplace and in particular their research identities. From our analysis of these interviews, we are able to offer a contribution to the conversation about the institutional cultures of this relatively new institutional type and the possibilities of reimaging its future. 
Our focus on the research aspects of academic work is important because five Universities of Technology refer to research directly in their vision and mission statements and all refer to research in their strategic plans as a focus of the institution. This might be unsurprising given that research is generally considered to be a key function of a university (Graham, 2013), but under apartheid, the binary divide between Universities and Technikons presented Technikons with few research opportunities or obligations (Reddy, 2006). In the Technikon sector, there was little expectation for Technikon lecturers to contribute to a research agenda (Powell and McKenna, 2009). With the institutional classification of 'University of Technology' in 2004 new expectations were placed on academics with significant effects on their identities.

\section{From Technikon to University of Technology}

Technikons had far stronger centralised control by the State over their programme offerings, budgets and curricula than universities did (Bunting, 2002) and this had effects on almost every aspect of their culture (Boughey, 2010). Technikons offered a career-focused, hands-on approach to education and training, and produced diplomates with knowledge that was immediately relevant in the workplace (Department of Education, 1997). Alongside the major formal distinction of Technikons offering nationally-developed diploma programmes and universities offering institutionally-developed general and professional degree programmes, was the distinction that universities were expected to produce research and offer postgraduate qualifications. But over the last few decades, there has been a drift as vocationally oriented programmes have been introduced in a number of strongly discipline-based universities (Gillard, 2004; Kraak, 2006) and Technikons began in the 1990s to offer postgraduate programmes. The drift accelerated once Technikons were reclassified as Universities of Technology, with these new institutions increasingly focusing on degree offerings, as can be seen from the re-curriculation process currently underway, which has resulted in a number of diplomas being converted into professional degrees.

The history of Technikons has been well documented (for example, Koen, 1989; Erasmus, 2008; Chetty, 2003) and such studies indicate that employment of lecturers in Technikons and promotion within them was largely based on industry experience. The extent to which an individual had ongoing connections to industry was considered a vital source of expertise and key to the integration of up-to-date workplace practices into the curriculum and important for the overseeing of workplace learning. Forming a research identity and engaging in research activities was neither expected nor encouraged by institutional structures.

The emergence of Universities of Technology as an institutional type had significant and sudden implications for those working within them. A number of national mechanisms steered Universities of Technology to focus on research. For example, the National Development Plan (2011) set targets for academics' qualifications, the funding formula privileges research output, and the Research Development Grant ${ }^{1}$ was provided as a ring-fenced allocation to institutions to

\footnotetext{
${ }^{1}$ As of 2018, the Research Development Grant is merged with the Teaching Development Grant to form the University Capacity Development Grant.
} 
improve research endeavours. Such system-wide drivers have led all institutions of all types to employ strategies to increase research, such as requiring improved academic qualifications of their staff and providing incentives for research outputs.

The change from Technikon to University of Technology shifted what is considered valuable within the institution and thus brought a demand for changes in academics' identities. Over the last fifteen years, most University of Technology academics have embarked on postgraduate studies. There has also been much more movement of academics between institutional types carrying the norms and expectations of one type into another.

\section{Methodology}

This article is based on a larger study (Gumbi, 2017) in which interviews were conducted with fifteen Dental Technology academics from three institutions to establish their experience of the emergence of the University of Technology as an institutional type. This article hones in on the data concerning how academic identities were being reimagined specifically in response to increased demands for research. The study participants' responses are undoubtedly conditioned by the nature of the professional field of Dental Technology, as we shall discuss in more detail later, but we would argue that the coherence between our findings and those in the literature suggest that these findings are broadly recognisable beyond the field of Dental Technology and beyond South Africa (for example, Harley, 2002; Findlow, 2012).

Ethical clearance was obtained from all three institutions and the participants provided informed consent to voluntarily participate in the study. Though the institutions involved in this study are publicly identifiable because Dental Technology is only offered at Durban University of Technology, Cape Peninsula University of Technology, and Tshwane University of Technology, the data is quoted in ways that anonymise each participant's institution as per the informed consent agreement. Participants were randomly allocated to a coding system of Lecturer 1 to Lecturer 15.

The fifteen academics were asked open-ended questions about their work, such as how long they had worked in the institution and where they had worked previously and what it was that they taught. The interview was largely conversational in nature with the respondents determining the direction it took and the interviewer asking probing questions to ensure shared understanding. It was planned that a question would be asked about research if the respondents did not raise the issue themselves but in all fifteen interviews, the issue of research was raised within minutes of the interview commencing.

The data was seen to describe the experiences of the fifteen academics which was then analysed with a Social Realist frame to identify some of the mechanisms from which these experiences emerged. Taking a Social Realist perspective on the data entails understanding that people's experiences emerge from a complex interplay of mechanisms. Archer (2000) shows that our identities can be understood in terms of the personal projects we set for ourselves and which we attempt to achieve. While each of us has agency, that is, the ability to act in ways that seek to 
achieve our personal projects, our agency is enabled or constrained by the structural and cultural mechanisms at play in the context.

Structures refer to social arrangements whereby the goods of society are dispensed. In this study, for example, the emergence of the structure of 'Universities of Technology' is of interest as are the national and international mechanisms driving such structures. The historical structure of 'Technikons' is also seen to continue to have a conditioning effect on what happens in the institution. Culture, in a Social Realist approach, refers to the ideologies and regular practices that occur in these institutions. The extent to which individual academics develop a research identity is thus seen to be tied to their personal projects which are in turn influenced by the structures and cultures within which they work.

Garraway and Winberg (2019: 42) describe institutional culture as being the 'sum total of the values, attitudes, styles of interaction, collective memories - the "way of life" of the university. While Garraway and Winberg (2019: 42) acknowledge that the institutional culture is 'known by those who work and study in the environment, through their lived experience', they do not distinguish between institutional culture and the agency of individuals. Drawing on Archer's demand for analytical dualism (2000) in undertaking a Social Realist analysis, we consider how individual academics' agency has emergent powers and properties separately from the powers and properties of the institutional culture. Archer (2000) argues that an understanding of such a distinction is necessary where change is desired.

There are dangers in describing the institutional cultures of all Universities of Technology and the research identities of all academics on the basis of interviews from fifteen academics from a specific field in just three out of the eight Universities of Technology. This is not the intention of this study. Archer (2000) argues that the aim of social research is not to discover generalizable truths but to begin to identify the conditions under which certain social phenomena emerge. By making sense of how individuals conceptualise their personal projects, enact their agency to this end, and are enabled or constrained by the structures and cultures within which they find themselves, we are able to identify some of the mechanisms at play. Institutional cultures are complex and vary even within a single university, and individuals' personal projects emerge from a myriad of experiences. Nonetheless, this study has identified a few mechanisms which need to be taken into account in heeding Garraway and Winberg's call (2019) to reimagine the future of Universities of Technology.

\section{Findings}

This paper discusses three main findings related to structural and cultural mechanisms enabling or constraining the development of research identities by academics in Universities of Technology. The first is about participants'understanding of research to be the acquisition of postgraduate qualifications, the second relates to how the institutional culture and structures enable or constrain research, and the third looks at structures external to the university in the form of a demand for research by the relevant industry, in this case Dental Technology. 


\section{Research as Postgraduate Qualification}

All participants commented on the demands placed on them related to research. Comments such as the following were common across the data:

Moving from the Technikon to the University, of course there is a huge challenge ... to lecturers, as research now became a fundamental component of the life of a lecturer. (Lecturer 11)

It's a University of Technology. Here the difference might be that they're prompting you towards doing a Master's, and in our era, they didn't prompt you to do a Master's. (Lecturer 10)

While reference to research was ubiquitous in the data, it was discussed exclusively in terms of obtaining formal qualifications, with participants using terms such as 'doing research' and 'studying for a postgraduate qualification' interchangeably. There was no spontaneous mention of research engagement for non-qualification purposes in any of the interviews:

I've been told to do my research, encourage is not the word that I would use. (Lecturer 15 referring to the institutional demand that he improve his qualifications.)

The understanding of the participants that 'research' equated to the attainment of a postgraduate qualification suggests that the institutional culture was not one in which the university was understood to play a role as a knowledge producer for broader society. Garraway and Winberg (2019: 46) indicate that in their research, conceptions of the institution as needing to 'respond to the 4th industrial revolution, and so become a different, more advanced university' were held mainly by top management and indeed such goals seem disconnected from the identities expressed by participants in our study.

Within the participants' shared understanding that research equates to improving formal postgraduate qualifications, there was a distinction between those who drew on more instrumentalist understandings and those who perceived postgraduate study as being tied to their 'personal project' (Archer, 2000). The instrumentalist understanding saw research as an institutional requirement for the purposes of job security or promotion, rather than one complimentary to their own academic identities:

You know, if you want now to move up the ladder to say senior lecturer and that, then you must have as a minimum a doctorate, PhD. So that is things now that we have to grapple with. (Lecturer 15)

If you become a lecturer and you're in a permanent position, if you don't have your Master's you have a certain time to complete it and if you don't complete it you obviously lose your 
position there. So that's the incentive for people to do their Master's now I guess. (Lecturer 8)

In contrast to such comments, there was evidence that for at least three of the participants attaining a postgraduate qualification was something more central to their, largely aspirational, sense of academic identity:

I did it [Master's research] for myself because, I mean I know within our industry your Master's doesn't have as much value within the South African industry as maybe overseas. So, I did it for myself. (Lecturer 5)

The three participants who reflected that undertaking postgraduate study was tied to their academic identities expressed the view that attaining postgraduate qualifications had a positive effect on teaching:

I think the Master's comes with another aspect of capacity building for my teaching and then I can pass it on. (Lecturer 6)

I think research does make [a better teacher], one hundred percent to make sure they get better academics. (Lecturer 5)

But, for other participants, the focus on academics' postgraduate qualifications was seen to have negative effects on teaching:

... we advertised once for two years to get a chrome cobalt lecturer and do you know why? You get excellent people who could teach but can't be appointed as such because that person hasn't got a Master's degree or a Doctorate, he becomes a junior lecturer, and no person in his right mind who is successful, who is successful outside, is going to want to become a junior lecturer. (Lecturer 8)

We are only going to appoint people who've got degrees [but] who haven't worked yet and how are they going to teach it? You see the vicious cycle? (Lecturer 12)

One of the three Universities of Technology in this study had introduced the requirement that new academic appointees have to be in possession of a Master's qualification in order to lecture. The other two institutions had this as a strong recommendation and if anyone was appointed without such a qualification, achieving it was part of their probationary requirements. Some participants saw this as meaning that departments would be less likely to be able to attract academics with strong workplace experience as such people would be unlikely to hold the required postgraduate qualification. 
There was a frequent comment by those participants who had been working in Universities of Technology for some time that they were already adequately qualified and that the requirement to achieve further formal qualifications was unnecessary:

For me, the value is the lecturer's expertise in industry, I believe that newbies [new lecturers] need to be exposed to industry, and you've got to have to be exposed to industry. (Lecturer 1)

... okay, the Master's is not sufficient to address the practical side, that's my little perception on lecturing (Lecturer 10)

In some cases, the institutional push to undertake further study had an adverse effect on their academic identities. Their lack of a postgraduate qualification was now experienced as positioning these participants as novices despite their many years of experience in the profession and in the Technikon (now University of Technology) sector:

I posed the question: if you have lecturers in your system that have got so much experience but do not have the qualification, does that mean you just kick them out? What happens to them? (Lecturer 12)

For some participants, the institutional pressure on lecturers to achieve higher academic qualifications was better aligned to their personal project than for others. The data shows that some participants used their agency to make the most of opportunities offered by the institution to undertake further studies, while others experienced the pressure to improve their qualifications as a threat to their academic identities, which had emerged largely from their workplace expertise. The equating of research with the achievement of a postgraduate qualification was evident across all fifteen interviews, and there was not a sense that undertaking research was an ongoing and integral aspect to their academic identities.

\section{The intersection between institutional culture and pressure to do research}

While all the respondents indicated an increased pressure to improve their postgraduate qualifications, with statements such as 'Whether we agree with it or not, that's what the institution wants and that's what we need to do' (Lecturer 4), there was general consensus that the institutional cultures did not support them in this endeavour:

I must say for an institution that's pushing Master's $\cdots$, there's not a lot of assistance, that's my personal opinion. (Lecturer 14)

There was a concern that the institutional systems were rigid and had not adapted to the call for research engagement: 
There are currently [institutional] structures and research which are working against, for me, against Master's and doctorate students, and until those structures are sorted and the managers start questioning these structures, it's going to take Master's and doctorate students even a longer time than the stipulated period. (Lecturer 1)

Despite managerialism and pressures to performativity, individuals are still able to create spaces for exercise of their agency (Clegg, 2008) but the highly bureaucratic controls in the system constrained the agency of academics to undertake research and to develop a sense of themselves as researchers. Participants complained about the 'politics' of the institution whereby it was difficult to register for postgraduate qualifications in faculties other than their own as the funding would not then accrue to their department. They described the lengthy time periods in obtaining permission to register, proposal approval, ethical clearance and so on. In keeping with the findings of Garraway and Winberg (2019), there was a sense in the data that academics were being held back in their research endeavours by onerous finance and procurement procedures. Participants complained that some requests were challenged by administrators who had no expertise in the field. Academics were not able to make their own arrangements for buying materials or for travel and they needed to get multiple levels of approval which participants indicated could result in extensive delays. Only approved suppliers could be used which sometimes increased costs and led to further delays.

In research intensive universities, where academics are expected to undertake their work from the position of strong research identities, there is typically a higher degree of trust allowing for relatively straightforward research management processes (McKenna and Boughey, 2014) ${ }^{2}$ but, as White, et al. (2011) and Boughey (2010) indicate, Universities of Technology are generally hierarchical in nature and have extensive managerialism emerging from their histories as Technikons. The implications of hierarchical cultures on the development of academic identities has been noted in the literature on polytechnics in New Zealand (Maurice-Takerei, 2015), and post-1992 universities in the United Kingdom (Harley, 2002) and elsewhere.

Despite reference in the literature to the need for Universities of Technology to develop more supportive research cultures (Du Pré, 2010), the data suggests that the participants did not feel that it was their responsibility or within their capacity to build such a culture. There were regular calls in the data for improvements to the 'research culture' of the institution, however this was expressed as something 'the university' must do, rather than something that would be driven by the agency of the participants through academic structures such as Senate. This reflects the Technikon history where lecturers were employed specifically to teach on nationally approved programmes. It is worth noting, for example, that those teaching in Technikons were called 'lecturers' and that the designation of 'academic' only came into common usage at the time of the change to Universities of Technology.

\footnotetext{
${ }^{2}$ It has been argued that such research-intensive universities are also changing to more managerialist approaches with increased bureaucracy and monitoring and concomitant delays in spending (Seale and Cross, 2016; Maistry, 2012).
} 
The most common reason given for the resistance to undertaking research was the high teaching workload. The time and resources allocated to conduct research were argued to be insufficient and participants identified a tension between the development of a research (postgraduate) identity and the identity as an adept teacher of Dental Technology. Those interviewed in this study were generally critical of the support that the institutions provided to them to complete their postgraduate studies.

I was loaded with enough work, and sorry, you didn't have half the year [off] to do your Master's. (Lecturer 4)

The unfortunate part about it is time, you can't be a full time lecturer and expect to do a Master's, really. (Lecturer 3)

There are multiple reasons for the heavier teaching loads at Universities of Technology. The differing entrance requirements and the skewed socioeconomic demographics across the sector (Cooper, 2015) condition teaching and learning processes, but it is not only the nature of the student body that increases the teaching demands experienced by academics in Universities of Technology. Given the practical nature of many University of Technology courses, extensive hands-on laboratory or studio time is needed to acquire the requisite practices. The emergence of research as an additional requirement placed on academics in such institutions needs to be understood within this context of a focus on knowledge as practice.

The structure of knowledge in Universities of Technology can thus be seen to be a mechanism constraining the positioning of research as central to the institutional culture. It also affected academics' identities. Henkel (2005) argues that academics' primary identity relationship is to their discipline. But, generally speaking, academics educated in and working in the University of Technology sector do not have a clear disciplinary home from which to claim such an identity. University of Technology programmes are predominantly focused on 'regions' (Muller, 2009). Bernstein (2000) distinguishes between 'singulars', which have fairly strong boundaries between them and clear knowledge building rules, and 'regions', which draw from multiple academic disciplines and recontextualise this selection of knowledge to face outwards to the world of work (Winberg, et al., 2013).

The Dental Technology programme faces the world of work by preparing Dental Technologists who will make fixed and removable oral and extra-oral appliances and prostheses as prescribed by a dentist (Vahed, 2014; Skea, 2010). The focus on 'regions', rather than disciplines, in the University of Technology sector holds true for the Dental Technology programme as this preparation for the world of work requires varied levels of expertise in areas as disparate as Art, Anatomy, Engineering, and Chemistry. The Dental Technology programme does not include such knowledge in its original form, but rather recontextualises selected knowledge from these areas into the workplace focused subjects taught in the programme. 
While 'singulars' have very clear, albeit unwritten, rules as to what counts as legitimate knowledge and how that knowledge is expected to be articulated by its knowers, 'regions' are far less bounded and there is much less agreement about what should be included as legitimate knowledge and what kinds of dispositions are expected of its knowers (Maton, 2013). This makes the formation of an academic identity through a primary identity relationship with the discipline more challenging.

I think it is going to have to be a lot more theoretical, it will probably be a big challenge because the Dental Technology is very practical and we are going to have to change it. (Lecturer 15)

Picking up our conversation with Garraway and Winberg (2019), we can see that they also state that the lack of development of disciplinary knowledge has mitigated against a strong research agenda. For academics in Universities of Technology to develop strong research identities, there needs to be a strengthening of the conceptual underpinnings of the curriculum, while retaining the strong focus on professional context. When Garraway and Winberg (2019) call for more flexible institutional cultures, the nature of the knowledge project needs to be taken into account. Developing a 'nimble research agenda' (Garraway and Winberg, 2019: 48) will require a careful consideration of the relationship between conceptual depth and contextual relevance. There is a need for engagement with how practical know-how is underpinned by theoretical know-why in ways that address the close relationship between the university, the community and industry.

Shay (2012), Muller (2009), Winberg (2005), Winberg et al. (2013) and many others call for a more rigorous conceptualisation of practical workplace knowledge. There is a need for strengthening the theoretical spine of practice-based education in workplace focused qualifications if the University of Technology sector is to claim its rightful place in offering the country much needed principled practical knowledge. Such a process requires academics who have a strong sense of their own value and who are able to see the connections between their own production of knowledge and the demands of the workplace. This article argues that the interplay between institutional structures and cultures are not always enabling of such connections being meaningfully made.

\section{Lack of industry demand for research}

As we have shown, and as with most programmes offered at Universities of Technology, many of the academics in this study were experienced industry personnel who were only introduced to research engagement when the focus of the institution shifted and demands were made for them to improve their academic qualifications. The participants in this study explained that their industry, Dental Technology, did not make demands for research and this constrained the extent to which there would be an interest in undertaking Dental Technology research. This may be specific to Dental Technology and the way in which it is practiced in South Africa. Participants 
indicated that there is little recognition within the Dental Technology industry of individuals who engage in research:

I understand the value of having a Master's degree as an academic because of the university structures and higher education and the need from that perspective. From a Dental Technology perspective, you're not going to get Master Dental Technician because Master's is not necessarily a requirement or it's not needed in industry. (Lecturer 1 )

Master's was not regarded as valuable, it's not regarded as something valuable in my industry. They say 'How's your Master's going to help you in industry?' They don't see the value of it, unless you're pursuing an academic career. (Lecturer 9)

The interplay between the institutional demand for improved qualifications among academics and the lack of a clear research direction in the relevant industry led to an interesting phenomenon emerging in the research: much of the postgraduate research being undertaken by academics within Dental Technology departments was not focused on the field of work at all:

The things [academics are] doing the research on now are sometimes not Dental Technology related, we are practical. (Lecturer 12)

I feel that the research though is not being swayed in a direction that should be practical... and no one is doing research that is going to improve my life as a Dental Technician. (Lecturer 2)

Some of the postgraduate studies being undertaken as M.Tech qualifications in Dental Technology were more related to educational, entrepreneurial or social issues, such as research on the introduction of a clinical curriculum (Mqadi, 2009), student recruitment and retention (Dlamini, 2017), the need for corporate social responsibility in the Dental Technology sector (Zondi, 2015) and the effects of the transition to Universities of Technology (redacted for review). This was a concern for many of the participants:

It is all soft things that they are doing it on, it has got no real benefit to Dental Technology. (Lecturer 8)

I just have a feeling that if people want to be academics, they would concentrate more on the classical research. (Lecturer 3)

If you go to research in a big way in Dental Technology, you must make sure that that research is Dental $\cdots$ I am very worried about the fact that so many of our Master's students are doing Master's in other areas. But we need people who are also doing research in the 
hard Dental Technology stuff, the material side, the technology, the development of techniques and equipment and instrumentation and all of those things because then we're really building depth in the profession itself. (Lecturer 1 )

In fields where there is little demand by the target industry for research to be undertaken, it would seem more difficult for University of Technology academics to take on a research identity. Garraway and Winberg's (2019) call for a dual-role researcher who maximises the links to industry and brings a new expertise to the relationship seems a direction worth exploring. The implications for how the knowledge in the field is conceptualised are significant.

This finding, that developing a research identity is constrained by the lack of demand for research by the relevant industry, may well not be generalisable across many departments. But it does highlight the need, raised by Garraway and Winberg, for a more nuanced and sophisticated understanding of the relationship between the institution, industry, and community.

\section{Conclusion}

Despite increases in publication outputs and postgraduate graduations, Universities of Technology continue to contribute a very small percentage of research in the South African higher education sector (Cloete, et al., 2015; CHE 2019). In this paper, we have argued that this is in part because being research active is not yet seen to be an integral aspect of many academics' identities.

Institutional structures and culture constrain the development of such identities. Heavy teaching loads associated with the hands-on development of complex workplace practices were seen to constrain the possibilities for research endeavours and the structure of knowledge in many fields made a clear research focus less easy to identify.

The hierarchical nature of Universities of Technology was seen, in part, to account for the extent to which the participants in this study understood the development of a research culture to be something that 'the institution' should provide and something that was external to their own realms of agency. Managerialist processes for running research projects were identified as constraining mechanisms.

The study also raised the issue that if the target workplace did not demand or value research, then it was more difficult for University of Technology academics to undertake research activities. There would seem to be a need for some creative work to be done in this regard in ways that allow for research to be undertaken which aligns well to the workplace identity and which has the potential to strengthen the conceptual core of the curriculum through a careful deliberation of the teaching-research nexus.

Our findings accord with Garraway and Winberg's contention (2019) that the first need is for recognition that there is a problem that needs to be addressed. Paying attention to how academics' experience the expectations placed upon them as being congruent or contradictory to their identities is important if change is to be achieved (Clegg, 2008). Undertaking change at 
the level of institutional structures and cultures will, we have argued, be severely undermined if the identities of individual academics are not taken carefully into account.

\section{Author Biographies}

Thobani Gumbi is a registered dental technologist and worked as such before joining Durban University of Technology in 2013. He is Acting Head of Department of Dental Sciences. Thobani's interests include institutional and academic identities, curriculum design, and work integrated learning in Universities of Technology, an issue he is exploring for his doctorate.

Sioux McKenna is the Director of Postgraduate Studies at Rhodes University where she also runs a PhD programme in social justice in higher education. Sioux is the project manager for a number of international collaborations, including a national supervision development course, Strengthening Postgraduate Supervision (www.postgradsupervision.com), and an online Creative Commons site, Enhancing Postgraduate Environments (www.postgradenvironments.com).

\section{References}

Archer, M. S. 2000. Being Human: The Problem of Agency. Cambridge: Cambridge University Press.

Bernstein, B. 2000. Pedagogy, Symbolic Control and Identity: Theory, Research, Critique - Revised Edition. New York: Rowman \& Littlefield.

Boughey, C. 2010. Analysing teaching and learning at the Universities of Technology: A tribute to Terry Volbrecht (Presentation). Rital Conference: Cape Peninsula University of Technology.

Bunting, I. 2002. The higher education landscape under apartheid. In Cloete, N., Maassen, P., Fehnel, R., Moja, T., Gibbon, T. \& Perold, H. (eds.). Transformation in Higher Education: Global Pressures and Local Realities in South Africa. Cape Town: Juta, 35-52.

Chetty, R. 2003. Research and development in technikons: Lacunae and challenges. South African Journal of Higher Education, 17(1): 9-15.

Clegg, S. 2008. Academic identities under threat? British Educational Research Journal, 34(3): 329 345

Cloete, N., Mouton J. \& Shepard C. 2015. Doctoral education in South Africa policy, discourse and data. Cape Town: African Minds.

Cooper, D. 2015. Social Justice and South African University Student Enrolment Data by "Race", 1998-2012: From "Skewed Revolution" to "Stalled Revolution". Higher Education Quarterly, 69(3): 237-262.

Council on Higher Education. 2019. Vital Statistics 2017. Pretoria: CHE.

Department of Education. 1997. Education White Paper 3: A Programme for the Transformation 
of Higher Education. Pretoria: Government Printers.

Dlamini, P. C. 2017. The factors associated with student recruitment and student recruitment and student profiles in dental technology at a university of technology. Unpublished Master of Technology Thesis, Durban University of Technology, Durban.

Du Pré, R. 2010. Universities of Technology in the context of the South African higher education. Kagisano: Journal of the Council on Higher Education, 7, 1-42.

Erasmus. 2008. Research at technikons: The journey from apprenticeship training to technological degrees. Unpublished PhD diss., University of Stellenbosch, Stellenbosch.

Findlow, S. 2012. Higher education change and professional-academic identity in newly 'academic' disciplines: the case of nurse education. Higher Education, 63: 117-133.

Garraway, J. \& Winberg, C. 2019. Reimagining futures of universities of technology. Critical Studies in Teaching and Learning, 7(1): 38-60.

Gillard, E. 2004. Council on Higher Education. Considerations on the designation and nomenclature of higher education institutions. Pretoria: Government Printers.

Graham, G. 2013. The University: A critical comparison of three ideal types. Kagisano: Aims of Higher Education, 9: 5-22

Gumbi, T. 2017. An investigation into Dental Technology lecturers' discourses of academic identity formation within the emergence of Universities of Technology in South Africa. Unpublished Master of Technology Thesis, Durban University of Technology, Durban.

Harley, S. 2002. The impact of research selectivity on academic work and identity in UK universities. Studies in Higher Education, 27(2): 187-205.

Henkel, M. 2005. Academic identity and autonomy in a changing policy environment. Higher education Journal, 49(1-20): 155-176.

Koen, H. 1989. The role of technikons in research. South African Journal of Science and Technology, 8(1): 35-36.

Kraak, A. 2006. 'Academic drift' in South African universities of technology: Beneficial or detrimental? Perspectives in Education, 24(3): 135-152

Maistry, S. M. 2012. Confronting the neo-liberal brute: Reflections of a higher education middlelevel manager. South African Journal of Higher Education, 26(3): 515-28.

Maton, K. 2014. Knowledge and Knowers. London: Routledge

McKenna, S. \& Boughey, C. 2014. Argumentative and trustworthy scholars: the construction of academic staff at research-intensive universities. Teaching in Higher Education, 19(7): 825834.

Mqadi, N. P. 2009. Perceptions on the addition of clinical practice to the dental technology curriculum. Unpublished Master of Technology Thesis, Durban University of Technology, Durban. 
Muller, J. 2009. Forms of knowledge and curriculum coherence. Journal of Education and Work, 22(3): 205-226

National Planning Commission. 2011. National Development Plan: A Vision for 2030. Pretoria: Government Printers.

Powell, P. \& McKenna, S. 2009. 'Only a name change': The move from Technikon to University of Technology. The Journal of Independent Teaching and Learning, 4: 37-58

Reddy, J. 2006. The reclassification of technikons to universities of technology. Kagisano: Journal of the Council on Higher Education, 5, 24-50.

Seale, O. \& Cross, M. 2016. Leading and managing in complexity: The case of South African deans. Studies in Higher Education, 41(8): 1514-1532.

Shay, S. 2012. Educational development as a field: Are we there yet? Higher Education Research \& Development, 31(3): 311-323

Skea, A. 2010. The Professionalization of Dental Technology. Unpublished Master of Technology Thesis, Durban University of Technology, Durban.

Vahed, A. 2014. Ensuring the quality of pedagogy through games in Dental Technology at a selected university. Unpublished Doctor of Technology diss., Durban University of Technology, Durban.

White, K., Carvalho, T. \& Riordan, S. (2011). Gender, power and managerialism in universities. Journal of Higher Education Policy and Management, 33(2), 179-188.

Winberg, C. 2005. Continuities and discontinuities in the journey from technikon to university of technology. South African Journal of Higher Education, 19 (2), 189-200.

Winberg, C., Engel-Hills, P., Garraway, J. \& Jacobs, C. 2013. Professionally-oriented knowledge and the purpose of professionally-oriented higher education Kagisano: Journal of the Council on Higher Education, 9, 98-120.

Zondi, M. M. P. 2015. Corporate Social Responsibility in the Dental Technology Industry in Kwazulu-Natal. Unpublished Master of Technology Thesis, Durban University of Technology, Durban. 